\title{
EEG Patterns and Performance When Facing the Cardinal Directions
}

\author{
Frederick T. Travis ${ }^{1}$, Jonathan B. Lipman ${ }^{2}$, Niyazi Parim ${ }^{1}$, Peter L. Hodak ${ }^{1} \&$ Jacqueline J. Leete $^{3}$ \\ ${ }^{1}$ Center for Brain, Consciousness and Cognition, Maharishi International University, Fairfield Iowa 52557, USA \\ ${ }^{2}$ Institute for Maharishi Vedic Architecture, Maharishi International University, Fairfield Iowa 52556, USA \\ ${ }^{3}$ Neuroscience and Behavior Department, Wesleyan University, Middletown, Connecticut 53562, USA \\ Correspondence: Frederick Travis, 1000 North 4th Street, MR 683, Fairfield, IA 52557, United States of \\ America.
}

Received: March 20, 2021

Accepted: April 19, 2021

Online Published: April 21, 2021

doi:10.5539/ijps.v13n2p28

URL: https://doi.org/10.5539/ijps.v13n2p28

\begin{abstract}
1) Background and Objectives: Position in space and passage of time are encoded in the firing of thalamic, hippocampal and entorhinal cortices in rodents. Head direction cells have been reported in freely moving monkeys, and differential brain patterns have been observed in humans while playing a navigation video game and in response to changes in electromagnetic fields. The sensitivity of organisms to environmental and electromagnetic cues could explain recommendations from a traditional system of architecture, Vastu architecture, which recommends aligning homes to the cardinal directions. 2) Hypothesis: Vastu architecture predicts that facing east and north are more advantageous than facing west and south. If facing east and north are more advantageous, then subjects should show distinct EEG patterns and improved performance when facing east and north compared to west or south. 3) Materials and Methods: EEG coherence patterns from 32-channel EEG and time-to-complete jigsaw puzzles were compared while subjects faced the four cardinal directions. 4) Results: When facing east and north, subjects' frontal beta2 and gamma EEG coherence were significantly higher, and they assembled jigsaw puzzles significantly faster than when facing west or south. 5) Discussion: The brain findings fit the performance data. Better focus, which would reasonably be related with faster performance, is associated with higher levels of beta2 and gamma coherence. 6) Conclusion: These data support the possibility that the human brain may be sensitive to cardinal directions. This highlights how intimately we are connected to the environment and suggests a factor that may be important in orienting work spaces and designing class rooms.
\end{abstract}

Keywords: architecture, cardinal directions, EEG coherence, head direction cells, Vaastu

\section{Introduction}

The physical environment appears to be encoded in patterns of firing in thalamic, hippocampal, and entorhinal neurons. O'Keefe, in 1971 first reported increased firing rates in hippocampal cells when rats moved to different areas of their maze (O'Keefe \& Dostrovsky, 1971). Working with O'Keefe, May-Britt and Edvard Moser identified 'grid' cells in the rat entorhinal cortex that fire when the animal nears points of a regular grid that span the environment (Hafting et al., 2005; Moser et al., 2017). These three were awarded the Nobel prize in 2014 for their findings (Abbott \& Callaway, 2014).

A recent article in Scientific American details the interconnected subcortical networks that encode an organism's position in space and passage of time (Moser \& Moser, 2016). These mental maps include: place cells in the hippocampus that consistently fire when one is in a specific place in a familiar spatial field (O'Keefe et al., 1975), grid cells that provide a neural representation of space with networks at the top of the entorhinal cortex mapping shorter distances and those at the bottom of the cortex mapping larger distances - up to meters between grid points (Fyhn et al., 2008), border cells that mark major borders in the environment (Santos-Pata et al., 2017), and head direction cells that fire maximally as the organism faces different directions (Butler et al., 2017; Taube, 1995). These networks were identified in rats, because depth electrodes could be used to study deep brain structures.

Head direction cells in the presubiculum, a structure that is next to the hippocampus, have been measured in freely moving monkeys. The firing rates of these cells were up to 100 times higher when the monkeys faced one direction than when facing others, with a tuning of 76 degrees (Butler et al., 2017). These cells fired even when 
the viewing details were obscured, or the room darkened suggesting that these cells are sensitive to direction and not visual stimuli.

Research suggests that the environment may be mapped in human brain functioning as well. One study reports differential firing patterns in neurosurgical patients playing a navigation video game when they moved in a clockwise compared to a counterclockwise path in the video game (Jacobs et al., 2010). These cells appeared to encode both location and direction information. Another study reports that EEG patterns in the 6-12 $\mathrm{Hz}$ band were significantly reduced when current was sent through three nested sets of orthogonal coils compared to no-current conditions (Wang et al., 2019).

Over 5,000 years ago, the system of architecture in the Vedic tradition, Vastu architecture, recommended that houses and rooms be orientated to the cardinal directions. Orientation of the physical structure could align the activity in the building to the cardinal directions. Vastu architecture predicts that facing east and north are more advantageous than facing west and south (Lipman et al., 2021).

\subsection{Study Hypothesis}

If facing east and north are more advantageous, then subjects should show different EEG patterns and have better performance when facing east and north compared to west or south.

\section{Materials and Methods}

\subsection{Subjects}

Twenty-eight subjects responded to posters advertising a study of brain functioning while completing jigsaw puzzles. Their average age was $50.0 \pm 20.8$ years, ranging from 18 to 80 years in age. Eleven were female. All were mentally and physically healthy. They were all right-handed.

Subjects were recruited to a study of jigsaw puzzles to keep them blind to the study hypothesis. The blinding appeared to have worked. No one asked if we were testing brain patterns and head direction. The experimenter emphatically pressed the stopwatch after each puzzle and gave subjects feedback on how fast they were.

\subsection{Procedure}

Subjects came into the university Brain Center individually in the late afternoon. They filled out consent forms while 32 sensors were applied in the 10-10 system with a forehead ground and left and right earlobe references. Resistance was $<10 \mathrm{k} \Omega$ at each sensor. This study was approved by the university Institutional Review Board. To maintain confidentiality, subject numbers were used in the data files.

Subjects then moved to a table in the Brain Center that was aligned with the cardinal directions. Four jigsaw puzzles were piled at each place around the table. Each jig saw puzzle contained 24 pieces.

We used quasi-randomization so that an equal number of subjects would start facing each of the four cardinal directions, and that their first puzzle would be randomly one of the four. Thus, a specific cardinal direction would not have the same puzzle for all subjects.

The time to complete the puzzle was recorded in tenths of a second. EEG was recorded with the BIOSEMI ActiveTwo System (www.BIOSEMI.COM) when subjects assembled each jigsaw puzzle. When finished with one puzzle, the subject stood up and moved to the next chair, moving clockwise. All data were digitized online at 256 points/sec, with no high or low frequency filters, and stored for later analyses using Brain Vision Analyzer.

This procedure resulted in seven subjects who began facing east, seven who began facing north, and so on. The puzzles at each cardinal direction were also randomized. Twice the first direction that subjects started with had puzzle 1, twice puzzle 2, twice puzzle 3 and once puzzle 4 .

\subsubsection{Test Instruments: Jigsaw Puzzles}

The puzzles contained 24 pieces and were recommended for ages 5 years and older. We used 24-piece-puzzles rather than more complex puzzles, such as 100-piece puzzles, for three reasons. First, more difficult puzzles would take longer to complete, leading to testing fatigue and a longer recording session. Second, testing fatigue could lead to subject reactivity, and subjects might be less inclined to give full attention to assembling the third and fourth puzzles. Third, testing fatigue could lead to more movement artifacts that would contaminate the EEG. 


\subsection{Data Analysis: EEG}

The EEG data were analyzed using Brain Vision analyzer. Three minutes of raw EEG were selected during the puzzle periods. The raw EEG was visually inspected for body movement, electrode slipping, or eye artifacts, manually marked and not included in the spectral analyses. Raw data were re-referenced to averaged linked ears, digitally filtered in a $2.0-50 \mathrm{~Hz}$ band pass filter with a $48 \mathrm{~dB}$ roll off, and fast Fourier transformed in 2-s epochs, using a Hanning window with a $10 \%$ onset and offset.

Coherence was calculated in $0.5 \mathrm{~Hz}$ bins in six frequency bands - delta $(0-4 \mathrm{~Hz})$, theta $(4-8 \mathrm{~Hz})$, alpha1 $(8-10$ $\mathrm{Hz})$, alpha2 (10-12 Hz), beta1 $(12-20 \mathrm{~Hz})$, beta2 $(20-30 \mathrm{~Hz})$, and gamma $(30-50 \mathrm{~Hz})$. EEG coherence patterns reflect functional coupling (Thatcher et al., 1986), information exchange (Petsche et al., 1997), and functional co-ordination (Gevins et al., 1989) between brain regions, which could reflect activity of subcortical areas. To reduce multiple comparisons, coherence estimates were averaged over the 36 coherence pairs among the nine frontal sensors (AF3, AF4, F3, F4, F7, F8, Fz, FC1, FC2), the 36 possible pairs among the nine parietal sensors (PO3, PO4, P3, P4, P7, P8, Pz, CP1, CP2) and the four coherence pairs among frontal and parietal sensors (F3/P3, F4/P4, AF3/P3, AF4/P4).

\subsection{Data Analysis: Puzzles}

The time to complete the puzzle was recorded with a stopwatch in tenths of a second.

\subsection{Statistical Analysis}

A repeated-measures MANOVA was used to test coherence estimates, with direction as the repeated measure and three brain areas (frontal, parietal, or front-to-parietal) and seven frequencies as within variables (SPSS 13.0). Individual repeated measure ANOVAs were conducted if there were significant interaction effects.

\section{Results}

\subsection{Coherence Analysis during Puzzle Completion}

The omnibus repeated measures MANOVA with direction as the repeated measure and three brain areas and seven frequencies as within variables yielded significant brain $\mathrm{x}$ frequency interactions $(\mathrm{F}(12,324)=17.0, \mathrm{p}<$ 0.001). Thus, repeated measure MANOVAs were conducted within each brain area.

While there were no significant main effects or interactions in parietal and front-to-parietal coherence, there was significant direction-by-frequency interaction in frontal coherence. $(F(18,504)=1.8, p=0.020)$. Thus, individual repeated measure ANOVAs were conducted for frontal coherence within each frequency band. There were only significant direction effects in beta2 and gamma coherence (beta2: $F(3,84)=4.0, p=0.010$; gamma: $F(3,84)=$ $2.8, \mathrm{p}=0.045)$. The significant effects were linear with coherence being highest when facing east, then coherence when facing north, then west and lowest when facing south (beta2: $F(1,28)=6.2, p=0.019$; gamma $(\mathrm{F}(1,28)=5.1, \mathrm{p}=0.032)$. These coherence differences are seen in Figure 1. Beta2 and gamma frequencies are to the left of the figure and are circled.

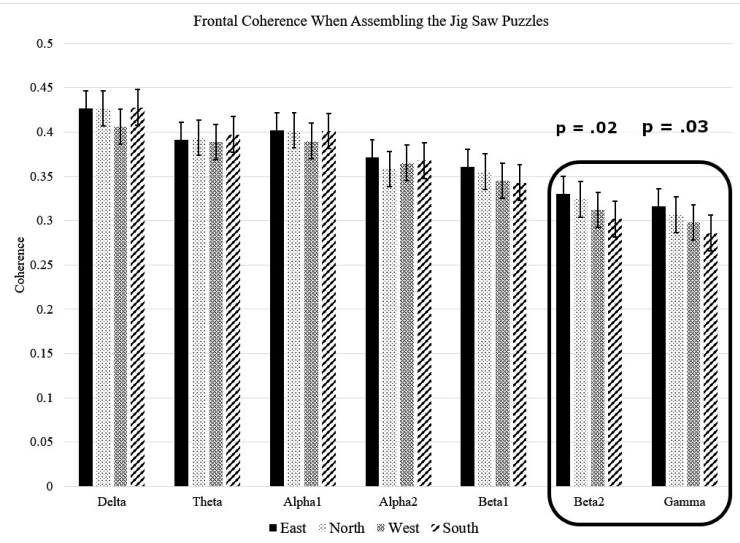

Figure 1. Frontal coherence averaged within the cardinal directions

Frontal coherence while assembling the puzzles was higher in beta2 and gamma frequencies when facing east or north, compared to facing west or south. 


\subsection{Average Time when Completing the Puzzles}

Times to complete the puzzles were averaged within each cardinal direction and compared with a repeated measures ANOVA. This analysis yielded a significant main effect for direction for puzzle-completion speed $(\mathrm{F}(1,27)=4.8, \mathrm{p}=0.037)$. The significant effects were linear with puzzle completion times faster when facing east, thennorth, west and south. These results are clearly seen in Figure 2, which presents time to complete the puzzle during the four directions.

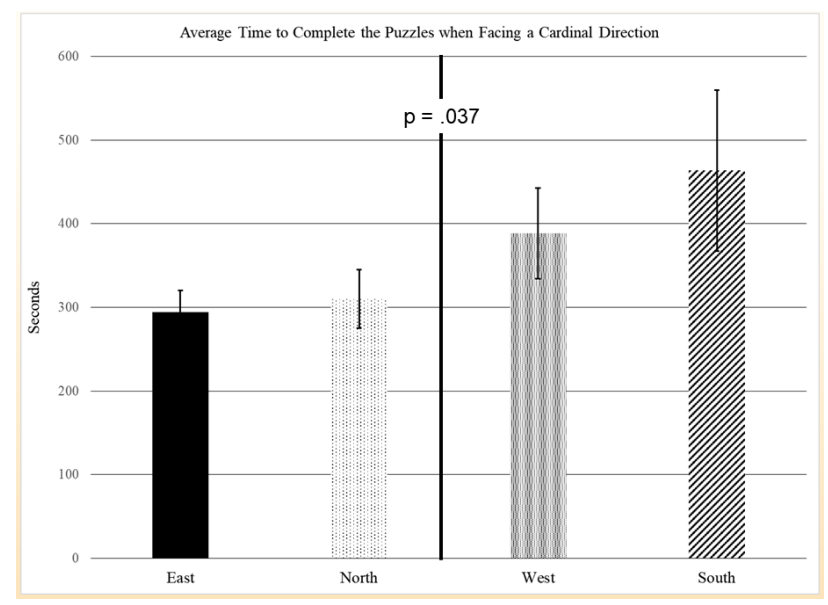

Figure 2. Time to complete puzzles

Average time to complete the four puzzles. Processing times were faster when facing east, then north, west and south.

\section{Discussion}

Subjects' frontal beta2 and gamma EEG coherence were significantly higher and they assembled puzzles significantly faster when facing east and north compared to west and south. The brain findings fit the performance data. Better focus, which would support faster performance, is associated with higher levels of beta2 and gamma coherence (Jensen et al., 2007). Beta2 and gamma coherence arise from local processing within short-range connections responsible for object recognition and goal-oriented behavior (Lubar, 1997; Singer, 1999). Thus, higher beta 2 and gamma coherence along with faster performance when facing specific cardinal directions support the possibility that the human brain may be sensitive to cardinal directions.

\subsection{Limitations of the Study and Future Research}

The design was strong: the sequence of puzzles and the beginning direction for the first puzzle were randomized, and the subjects were blind to the study hypothesis. However, the number of subjects was small $(\mathrm{N}=28)$. Future research could replicate these findings with a larger subject population and test the effect of head direction on real-world tasks such as student retention, complex problem solving or computer coding.

\section{Conclusion}

In this random assignment blinded study, head direction was associated with faster speed of assembling jigsaw puzzles and higher levels of beta2 and gamma coherence. These data support the possibility that the human brain may be sensitive to cardinal directions. It highlights how intimately we are connected to the external environment.

These findings could inform design decisions and explain variability in education research - the orientation of the desks in classrooms may influence student alertness and so learning, and in business research - the orientation of work stations could affect productivity. Future research can explore these possibilities.

\section{References}

Abbott, A., \& Callaway, E. (2014). Prize for place cells. Nature, 514(7521), 153. https://doi.org/10.1038/514153a

Butler, W. N., Smith, K. S., van der Meer, M. A., \& Taube, J. S. (2017). The Head-Direction Signal Plays a Functional Role as a Neural Compass during Navigation. Current Biology, 27(15), 2406. https://doi.org/10.1016/j.cub.2017.07.032 
Fyhn, M., Hafting, T., Witter, M. P., Moser, E. I., \& Moser, M. B. (2008). Grid cells in mice. Hippocampus, 18(12), 1230-1238. https://doi.org/10.1002/hipo.20472

Gevins, A. S., Bessler, S. L., Morgan, N. H., Cutillo, B. A., White, R. M., Greer, D. S., \& Illes, J. (1989). Event-related covariances during a bimanual visuomotor task. I. methods and analysis of stimulus- and response-locked data. Electroencephalography \& Clinical Neurophysiology, 74(1), 58-75. https://doi.org/10.1016/0168-5597(89)90052-X

Hafting, T., Fyhn, M., Molden, S., Moser, M. B., \& Moser, E. I. (2005). Microstructure of a spatial map in the entorhinal cortex. Nature, 436(7052), 801-806. https://doi.org/10.1038/nature03721

Jacobs, J., Kahana, M. J., Ekstrom, A. D., Mollison, M. V., \& Fried, I. (2010). A sense of direction in human entorhinal cortex. PNS, 107(14), 6487-6492. https://doi.org/10.1073/pnas.0911213107

Jensen, O., Kaiser, J., \& Lachaux, J. P. (2007). Human gamma-frequency oscillations associated with attention and memory. Trends Neurosciences, 30(7), 317-324. https://doi.org/10.1016/j.tins.2007.05.001

Lipman, Fergusson, L., Bonshek, A., Orme-Johnson, D., \& Schneider, R. (2021). The Impact of Maharishi Vastu Architecture on Health: A Review of Theory and Research. Medicina, 57.

Lubar, J. F. (1997). Neocortical dynamics: Implications for understanding the role of neurofeedback and related techniques for the enhancement of attention. Applied Psychophysiology and Biofeedback, 22, 111-126. https://doi.org/10.1023/A:1026276228832

Moser, E. I., Moser, M. B., \& McNaughton, B. L. (2017). Spatial representation in the hippocampal formation: a history. Nature Neuroscience, 20, 1448-1464. https://doi.org/10.1038/nn.4653

Moser, M. B., \& Moser, E. L. (2016). Where Am I? Where Am I Going? Scientific American, 314(1), $26-33$. https://doi.org/10.1038/scientificamerican0116-26

O'Keefe, J., \& Dostrovsky, J. (1971). The hippocampus as a spatial map. Preliminary evidence from unit activity in the freely-moving rat. Brain Research, 34(1), 171-175. https://doi.org/10.1016/0006-8993(71)90358-1

O'Keefe, J., Nadel, L., Keightley, S., \& Kill, D. (1975). Fornix lesions selectively abolish place learning in the rat. Experimental Neurology, 48(1), 152-166. https://doi.org/10.1016/0014-4886(75)90230-7

Petsche, M., Kaplan, S., von Stein, A., \& Filz, O. (1997). The possible meaning of the upper and lower alpha frequency ranges for cognitive and creative tasks. International Journal of Psychophysiology, 26, 77-97. https://doi.org/10.1016/S0167-8760(97)00757-5

Santos-Pata, D., Zucca, R., Low, S. C., \& Verschure, P. (2017). Size Matters: How Scaling Affects the Interaction between Grid and Border Cells. Front. Comput. Neurosci., 11, 65. https://doi.org/10.3389/fncom.2017.00065

Singer, W. (1999). Neuronal synchrony: A versatile code for the definition of relations? Neuron, 24(1), 49-65. https://doi.org/10.1016/S0896-6273(00)80821-1

Taube, J. S. (1995). Head direction cells recorded in the anterior thalamic nuclei of freely moving rats. Journal of Neuroscience, 15(1), 70-86. https://doi.org/10.1523/JNEUROSCI.15-01-00070.1995

Thatcher, R. W., Krause, P. J., \& Hrybyk, M. (1986). Cortico-cortical associations and EEG coherence: a two-compartmental model. Electroencephalography and Clinical Neurophysiology, 64(2), 123-143. https://doi.org/10.1016/0013-4694(86)90107-0

Wang, C. X., Hilburn, I. A., Wu, D. A., Mizuhara, Y., Couste, C. P., Abrahams, J. N. H., Bernstein, S. E., Matani, A., Shimojo, S., \& Kirschvink, J. L. (2019). Transduction of the Geomagnetic Field as Evidenced from alpha-Band Activity in the Human Brain. eNeuro, 6(2). https://doi.org/10.1523/ENEURO.0483-18.2019

\section{Copyrights}

Copyright for this article is retained by the author(s), with first publication rights granted to the journal.

This is an open-access article distributed under the terms and conditions of the Creative Commons Attribution license (http://creativecommons.org/licenses/by/4.0/). 